\title{
Mechanical Properties of Co-Extruded Aluminium-Steel Compounds
}

\section{Susanne Elisabeth Thürer ${ }^{1, a,{ }^{*}}$, Johanna Uhe ${ }^{2, b}$, Oleksandr Golovko ${ }^{1, \mathrm{c}}$, Christian Bonk ${ }^{2, \mathrm{~d}}$, Anas Bouguecha ${ }^{2, \mathrm{e}}$, Bernd-Arno Behrens ${ }^{2, \mathrm{f}}$, Christian Klose K $^{1, g}$} ${ }^{1}$ Leibniz Universität Hannover, Institut für Werkstoffkunde,
An der Universität 2, 30823 Garbsen, Germany

\author{
${ }^{2}$ Leibniz Universität Hannover, Institut für Umformtechnik und Umformmaschinen, \\ An der Universität 2, 30823 Garbsen, Germany \\ a thuerer@iw.uni-hannover.de, ${ }^{b}$ uhe@ifum.uni-hannover.de, ${ }^{c}$ golovko@iw.uni-hannover.de, \\ d bonk@ifum.uni-hannover.de, ${ }^{\mathrm{e}}$ bouguecha@ifum.uni-hannover.de, \\ f behrens@ifum.uni-hannover.de, ${ }^{9}$ klose@iw.uni-hannover.de
}

Keywords: co-extrusion, intermetallic phases, de-bonding shear stress

\begin{abstract}
Within the scope of the Collaborative Research Centre (CRC) 1153 novel process chains for the production of hybrid solid components by Tailored Forming are developed at the Leibniz Universität Hannover. The combination of e. g. aluminium with steel allows to produce hybrid compounds with wear-resistant functional surfaces and reduced weight. In these process chains, joining takes place as the first step to produce hybrid semi-finished products by friction welding, cladding, ultrasonic assisted laser welding or co-extrusion, which are subsequently subjected to various forming processes such as forging or impact extrusion. The coaxially joined hybrid semifinished components investigated in this work were produced by means of the lateral angular coextrusion (LACE) process using the aluminium alloy EN AW-6082 and the case-hardening steel $20 \mathrm{MnCr} 5$. These semi-finished products shall be suited to produce hybrid bearing bushings by die forging in a subsequent process step. Initial investigations for the determination of the process parameters and the appropriate tool geometry were made using a steel rod. In future investigations, a steel tube will replace the steel rod in order to produce hybrid semi-finished products, which can be fully integrated into the process chain. The mechanical properties of the profile were determined at different positions along its length. For this purpose, the quality of the joining zone between aluminium and steel as a function of the profile position was examined by means of push-out tests. Moreover, the mechanical properties of the aluminium component's longitudinal weld seam were determined by micro-tensile-tests.
\end{abstract}

\section{Introduction}

The use of different materials in a single part allows for the production of high performance components with reduced weight. Although the application of tailored blanks is already state of the art in sheet metal forming, the use of hybrid semi-finished workpieces is not common in bulk metal forming. For this reason, the aim of the Collaborative Research Centre 1153 is to realise new process chains to produce hybrid solid components with load-adjusted properties using semifinished workpieces joined prior to forming [1].

As one of the considered joining processes, co-extrusion represents an attractive solution to produce hybrid solid components with high specific strength and reduced weight. In general, there are two different process variants of co-extrusion. On the one hand, the reinforcing elements can be integrated within the extrusion billet. Thus, both the matrix material and the reinforcement will be formed by extruding the reinforced billet [2]. On the other hand, the reinforcing element, e. g. steel wires, can be fed into the deformation zone from outside the die [3]. In this case, only the matrix material is plastically deformed and the reinforcement remains undeformed. With the aid of a modified equal channel angular pressing process, co-extrusion of compound profiles can be achieved by feeding the matrix material at an angle of approx. $90^{\circ}$ into the deformation zone. This 
process was labelled lateral angular co-extrusion (LACE) by the authors. In [4], the feasibility of the co-extrusion of asymmetric aluminium-titanium compound profiles was shown. In this case, the aluminium was extruded perpendicular to the titanium profile and redirected inside the tool in order produce an asymmetric compound profile.

The interface properties of the extruded compound profile are of particular importance as they determine the properties and the formability of the hybrid component. Especially for the intended subsequent die forging process, the internal load transfer between the aluminium matrix and the reinforcing element as well as the mechanical properties of the weld seam are crucial factors for the performance of the hybrid co-extruded component. In order to evaluate and quantify the properties of the compound between matrix material and reinforcement, push-out tests are established for fibre- and wire-reinforced composites $[5,6]$. By pushing out a single fibre, the de-bonding shear strength can be measured. The functional principle and schematic load-displacement characteristic for push-out tests are shown in Fig. 1 . The de-bonding shear strength, $\tau_{\max }$, can be calculated using the data acquired in the push-out tests using Eq. 1 [5].

$\tau_{\max }=\frac{F_{\max }}{\pi d h}$

Here $F_{\max }$ denotes the maximum axial load, $d$ is the diameter of the fibre/reinforcement, and $h$ the thickness of the sample.

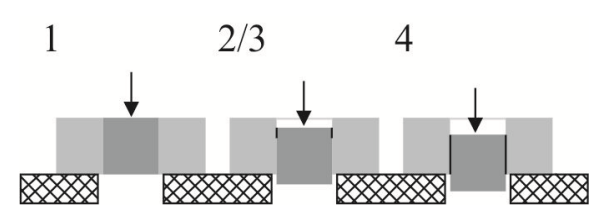

a)

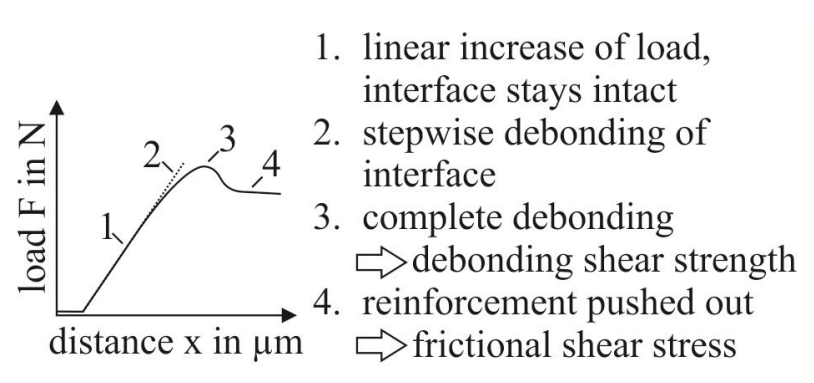

b)

Fig. 1: a) Functional principle of the push-out test; b) schematic load-displacement-graph of a fibre pushout test [6]

\section{Experimental Procedure}

\section{Co-Extrusion of aluminium-steel compound profiles}

The coaxial hybrid profiles were co-extruded with the LACE method using a $2.5 \mathrm{MN}$ laboratory extrusion press (Müller Engineering). The tool concept for the production of the hybrid profiles is shown in Fig. 2. The tool enabled extrusion of the aluminium alloy EN AW-6082 at an angle of $90^{\circ}$ between the punch direction and the exit port of the profile (the extrusion direction is marked with arrows in Fig. 2). This allowed a continuous feed of the steel rods $(20 \mathrm{MnCr} 5)$ into the welding chamber. The process results in semi-finished products in the form of round profiles of a steel rod embedded in aluminium. Due to the separation of the aluminium flow in the die, two longitudinal weld seams are formed during the co-extrusion process. With a diameter of $55 \mathrm{~mm}$ for the aluminium billet, $15.2 \mathrm{~mm}$ for the steel rod and an opening diameter of $28 \mathrm{~mm}$ for the die, the press ratio equalled 9:1. A supporting channel inside the tool prevented tilting of the steel rod during feeding. The reinforcing element was cleaned with ethanol prior to the extrusion process. The billets and the extrusion billet were preheated to $500{ }^{\circ} \mathrm{C}$ for $2 \mathrm{~h}$ and the temperature of the steel rod equalled room temperature at the beginning of each experiment. The die and the container were preheated to $500{ }^{\circ} \mathrm{C}$ as well. A ram speed of $2.0 \mathrm{~mm} / \mathrm{s}$ was used during the experiments. Finally, three hybrid profiles were produced with equal extrusion parameters using the LACE method for the mechanical testing. 


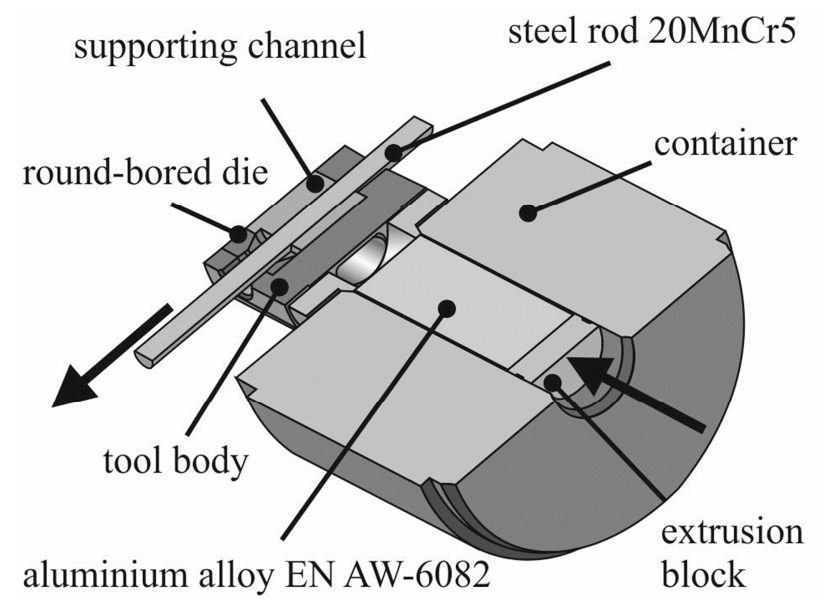

Fig. 2: Schematic cross sectional view of the LACE process tool with redirection of the aluminium alloy at an angle of $90^{\circ}$

The chemical compositions of the materials investigated in the present study were analysed using spark spectroscopy spectrometry (Spectromaxx from Spectro). The results obtained are summarised in Tables 1 and 2.

Table 1: Chemical composition of the aluminium alloy EN AW-6082 in wt.-\%

\begin{tabular}{ccccccccccc}
\hline Material & \multirow{2}{*}{ Al } & Si & Fe & $\mathbf{C u}$ & $\mathbf{M n}$ & $\mathbf{2}$ Mg & $\mathbf{C r}$ & $\mathbf{Z n}$ & $\mathbf{T i}$ \\
\hline \multirow{2}{*}{ EN AW-6082 } & \multirow{2}{*}{ balance } & 1.34 & 0.20 & 0.06 & 0.77 & 0.91 & 0.02 & 0.13 & 0.23 \\
& & \pm 0.005 & \pm 0.006 & \pm 0.001 & \pm 0.003 & \pm 0.008 & \pm 0.0003 & \pm 0.0008 & \pm 0.0009 \\
\hline
\end{tabular}

Table 2: Chemical composition of the steel $20 \mathrm{MnCr} 5$ in wt.- $\%$

\begin{tabular}{ccccccc}
\hline Material & Fe & $\mathbf{C}$ & $\mathbf{S i}$ & $\mathbf{M n}$ & $\mathbf{C r}$ & $\mathbf{S}$ \\
\hline \multirow{2}{*}{$20 \mathrm{MnCr} 5$} & \multirow{2}{*}{ balance } & 0.21 & 0.25 & 1.19 & 1.11 & 0.03 \\
& & \pm 0.008 & \pm 0.002 & \pm 0.01 & \pm 0.006 & \pm 0.002 \\
\hline
\end{tabular}

\section{Experimental Setup}

For a statistical analysis, all specimens were obtained from comparable locations of the three hybrid profiles using wire-cut electrical discharge machining. Specimens for metallographic analysis, tensile tests, and push-out tests were taken from each profile as demonstrated in Fig. 3 a). The specimens for the microstructural investigations $\left(\mathrm{M}_{\mathrm{x}}\right)$ were cut out of the profile after a length of $15 \mathrm{~mm}$ (beginning=b), $220 \mathrm{~mm}($ middle $=\mathrm{m})$ and $572.5 \mathrm{~mm}(\mathrm{end}=\mathrm{e})$ of the aluminium cladding. The cross section of the samples had a diameter of $28 \mathrm{~mm}$ and a height of $5 \mathrm{~mm}$. These specimens were prepared metallographically. The interface between aluminium and steel was analysed by light microscopy. The longitudinal weld seams were investigated using a $\mathrm{H}_{2} \mathrm{SO}_{4} / \mathrm{HF}$ etching solution. Additionally, the specimens for the tensile tests of the aluminium-aluminium weld seam $\left(\mathrm{T}_{\mathrm{x}}\right)$ were taken from locations adjacent to those of the metallographic samples $(20 \mathrm{~mm}, 225 \mathrm{~mm}$ and $577.5 \mathrm{~mm})$. By etching the beginning $(15 \mathrm{~mm})$ and the end of the profile $(572.5 \mathrm{~mm})$ with a solution consisting of $\mathrm{H}_{2} \mathrm{SO}_{4}$ and $\mathrm{HF}$, an extrapolation of the position of the longitudinal weld seam along the entire profile length was possible. This allowed for a calculation of suitable positions of the specimens for the tensile tests with the weld seams within the gauge length. Due to the small size of the extruded profile, micro-tensile specimens with a thickness of $2.5 \mathrm{~mm}$ and a total length of $12 \mathrm{~mm}$ were used. The corresponding geometry of the specimen is shown in Fig. $3 \mathrm{~b}$ ). The tensile test was performed using a load frame from Kammrath and Weiss $\mathrm{GmbH}$ with positivelocking clamping jaws. The specimens were preloaded with $50 \mathrm{~N}$ with an extension rate of $5 \mu \mathrm{m} / \mathrm{s}$. Subsequently, the specimens were metallographically prepared in order to examine whether the failure occurred in the weld seam area or in the aluminium matrix. As a reference, tensile tests were performed using identical specimens, taken from an extruded rod of aluminium alloy EN AW-6082. 


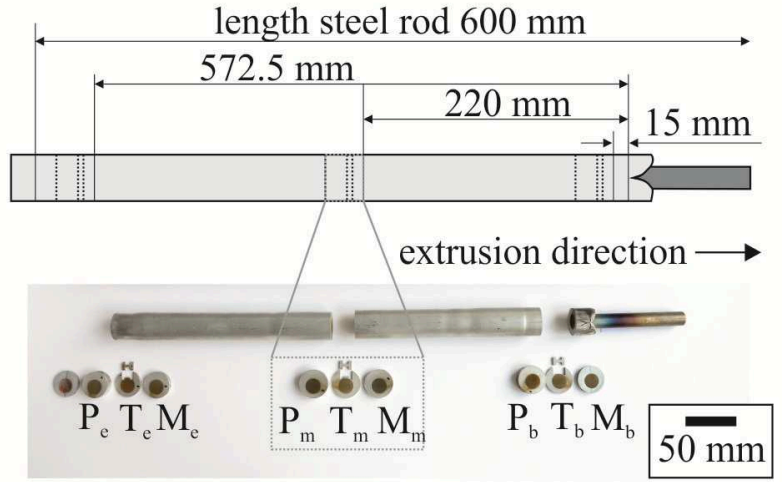

a)

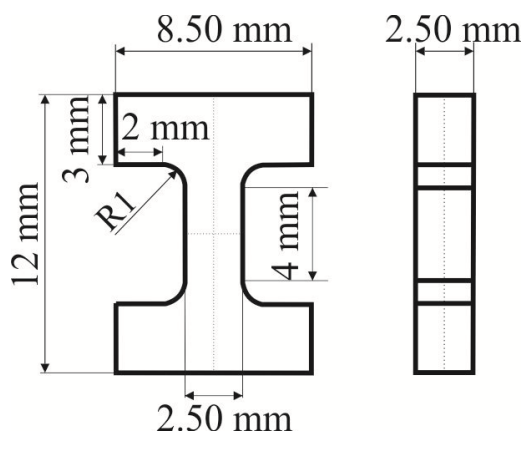

b)

Fig. 3: a) Hybrid profile with a total length of the aluminium cladding of approx. $600 \mathrm{~mm}$ showing the sample locations for the metallographic analysis, the tensile tests as well as the push-out tests; b) geometry of the specimen for the tensile test of the weld seam

The push-out specimens $\left(\mathrm{P}_{\mathrm{x}}\right)$ had a thickness of $10 \mathrm{~mm}$ (Fig. $3 \mathrm{~b}$ ) and were taken after $22.5 \mathrm{~mm}$, $227.5 \mathrm{~mm}$ and $580 \mathrm{~mm}$ of the aluminium. The reinforcement element had a diameter of $15.2 \mathrm{~mm}$ and allowed for a push-out test on a standard universal testing machine Z250 from Zwick. The samples were preloaded with $50 \mathrm{~N}$ and then loaded with an extension rate of $2 \mathrm{~mm} / \mathrm{min}$. The experimental setup of the push-out test is shown schematically in Fig. 1 a). The stop criterion was defined as $80 \%$ of the maximum force. The load-displacement-graphs were registered and the debonding shear strength was calculated following Eq. (1) using the measured maximum load.

\section{Results and Discussion}

\section{Metallography}

The cross-section of the hybrid profiles showed that the steel rod was not positioned coaxially in the aluminium matrix, as it can be seen in Fig. 4 a). However, the supporting channel of the die prevented tilting of the steel rod. At the beginning of the hybrid profiles, the weld seams were displaced laterally. This can be attributed to an uneven aluminium flow during the initial filling of the die. It was possible to determine a symmetric position of the weld seams after $20 \mathrm{~mm}$ of aluminium. By this means, the position for the tensile specimens, with the weld seam in the middle of the initial gauge length, was defined. This is shown schematically in Fig. 4 b). Small gaps between the aluminium and the steel rod of up to $400 \mathrm{~nm}$ width were observed via scanning electron microscopy over the entire length of the hybrid profiles.

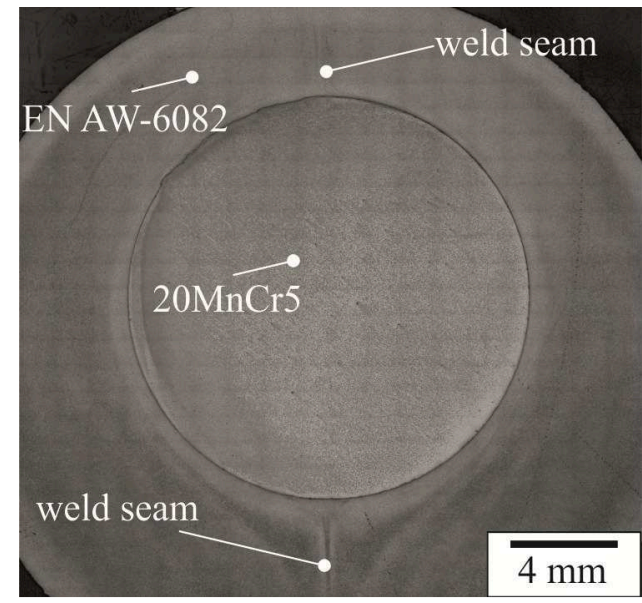

a)

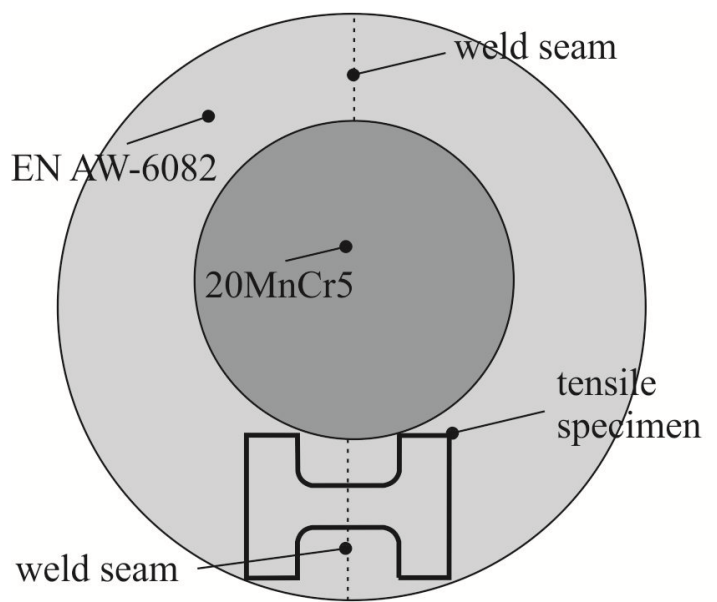

b)

Fig. 4: a) Cross-section of a hybrid profile etched with a solution consisting of $\mathrm{H}_{2} \mathrm{SO}_{4} / \mathrm{HF}$; b) schematic position of the tensile specimen in the cross-section 


\section{Tensile Tests}

The use of strain gauges was not feasible due to the small size of the tensile specimen geometry. This led to the use of load-displacement curves instead of stress-strain curves. Fig. 5 shows the load-displacement curves of the tensile specimens $T_{b}, T_{m}$, and $T_{e}$ (taken at $20 \mathrm{~mm}, 225 \mathrm{~mm}$ and $577.5 \mathrm{~mm}$ respectively) of the first hybrid profile. The maximum tensile strength decreases with increasing distance from the beginning of the profile. Thus, the determined averaged tensile strength of the aluminium-aluminium bond equalled $152 \mathrm{MPa} \pm 4 \mathrm{MPa}$ at the beginning of the profile. The specimens, $\mathrm{T}_{\mathrm{m}}$, from the middle of the profile provided a tensile strength of $147 \mathrm{MPa} \pm$ $3 \mathrm{MPa}$, whereas at the end of the profile an averaged tensile strength of $141 \mathrm{MPa} \pm 3 \mathrm{MPa}$ was calculated.

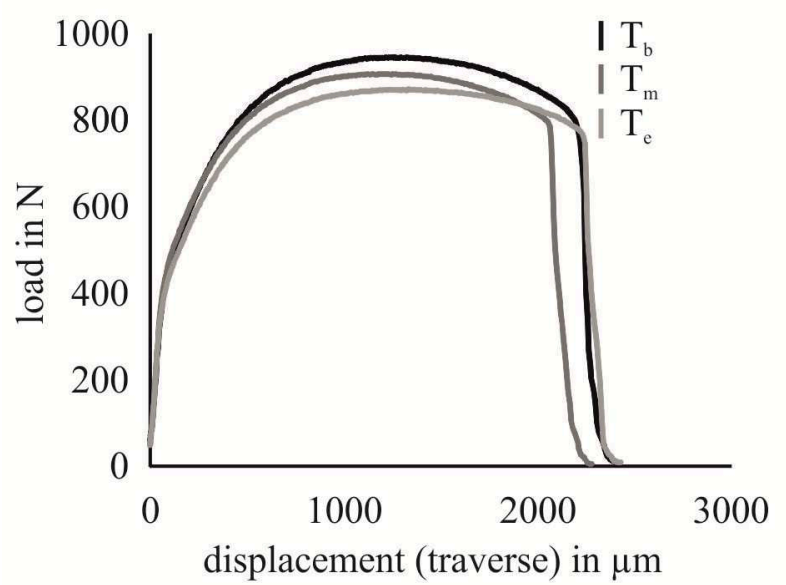

Fig. 5: Load-displacement curves of the tensile test of the specimens $T_{b}, T_{m}$, and $T_{e}$ of one hybrid profile

It was shown by metallographic investigations that the failure of the tested tensile specimens, $\mathrm{T}_{\mathrm{m}}$, from the middle of the profiles occurred in the longitudinal weld seam. Hence, the longitudinal weld seam cannot be seen in the testing area, as shown representatively in Fig. 6 a). In contrast, one of the tensile specimens, $T_{b}$, taken from the beginning of the profiles failed right next to the longitudinal weld seam. This particular specimen showed the lowest value for the maximum tensile strength with $148 \mathrm{MPa}$ compared to $156 \mathrm{MPa}$ and $152 \mathrm{MPa}$ for the others specimens taken at the same position, $\mathrm{T}_{\mathrm{b}}$. All samples, $\mathrm{T}_{\mathrm{e}}$, of the end of the hybrid profiles failed next to the weld seam. Consequently, failure of these specimens occurred in the aluminium matrix, as it is shown in Fig. 6 b).

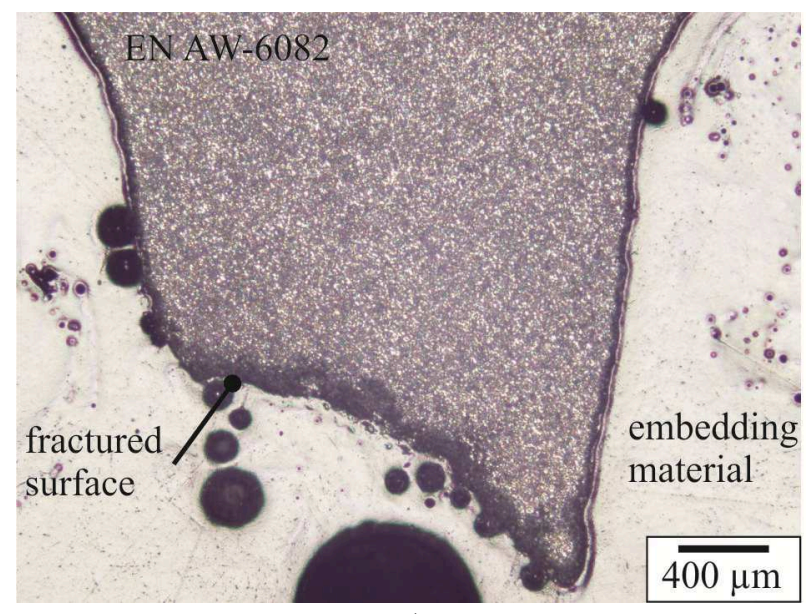

a)

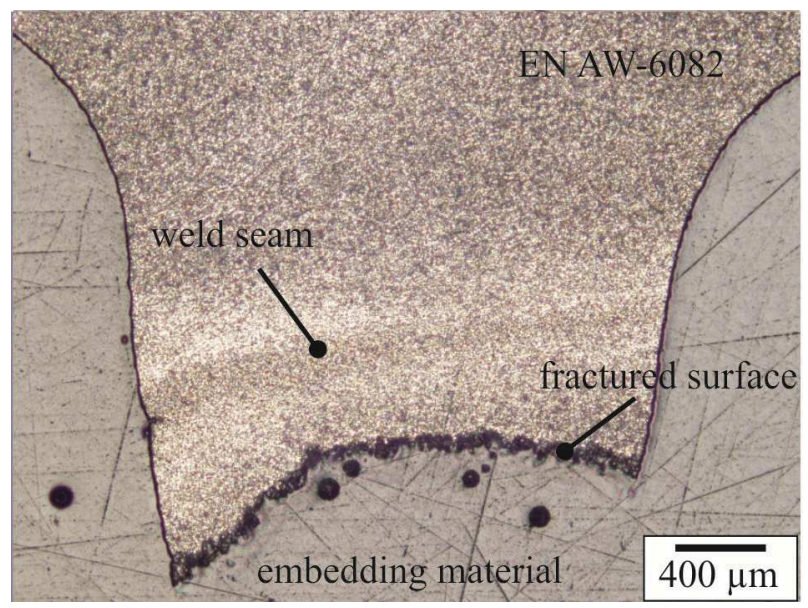

b)

Fig. 6: Light optical image of one part of tensile specimens after the failure: a) specimen $T_{m}$ fractured within the weld seam; $b$ ) specimen $T_{e}$ fractured next to the weld seam

The micro-tensile specimens were wire-cut whit keeping the calculated position of the profile's weld seam within the gauge length of the samples for each case. This led to small differences in the specimen geometry concerning the clamping surface, which must be taken into account. Therefore, the maximum tensile strength is then comparable over the entire length of the hybrid profile. 
Furthermore, the strength values of the specimens, which failed in the weld seam, and the specimens, which failed in the aluminium matrix next to the weld seam, were comparable. Because of a severe plastic deformation in the used modified equal channel angular pressing process, grain refinement and therefore, a higher tensile strength compared to the tensile strength of the reference specimens is expected [7]. The maximum tensile strength of the reference specimens consisting of extruded EN AW-6082 was $132 \mathrm{MPa} \pm 5 \mathrm{MPa}$. Thus, the maximum tensile strength of the specimens testing the weld seam complies with the tensile strength of the alloy. It must be taken into account, that the reference was not extruded using the LACE method and hence, the tensile strength of the reference specimens is lower due to a larger grain size. Consequently, a weld seam was produced over the total length of the profiles, which had a maximum tensile strength comparable with the reference specimen and the matrix material.

\section{Push-Out Tests}

The initial slopes of the force-displacement curves for the samples at the beginning, middle and end of the hybrid profiles were comparable and complied with the four stages of the loaddisplacement-graph of [6]. Fig. 7 shows a representative load-displacement-graph of the specimens $\mathrm{P}_{\mathrm{b}}, \mathrm{P}_{\mathrm{m}}$, and $\mathrm{P}_{\mathrm{e}}$ of one hybrid profile. At the beginning, the load increased to a maximum possible penetration depth. The specimen from the beginning of the profile, $\mathrm{P}_{\mathrm{b}}(22.5 \mathrm{~mm})$, showed premature failure with a maximum load of about $14 \mathrm{kN}$ and thus, a de-bonding shear stress of $29 \mathrm{MPa}$. With a load of about $47 \mathrm{kN}$, a maximum de-bonding shear strength of $99 \mathrm{MPa}$ was determined in the middle of the profile $\left(\mathrm{P}_{\mathrm{m}}, 227.5 \mathrm{~mm}\right)$. The specimen $\mathrm{P}_{\mathrm{e}}$ in the end of the profile showed premature failure with a maximum load of about $33 \mathrm{kN}$ and a de-bonding shear strength of $69 \mathrm{MPa}$.

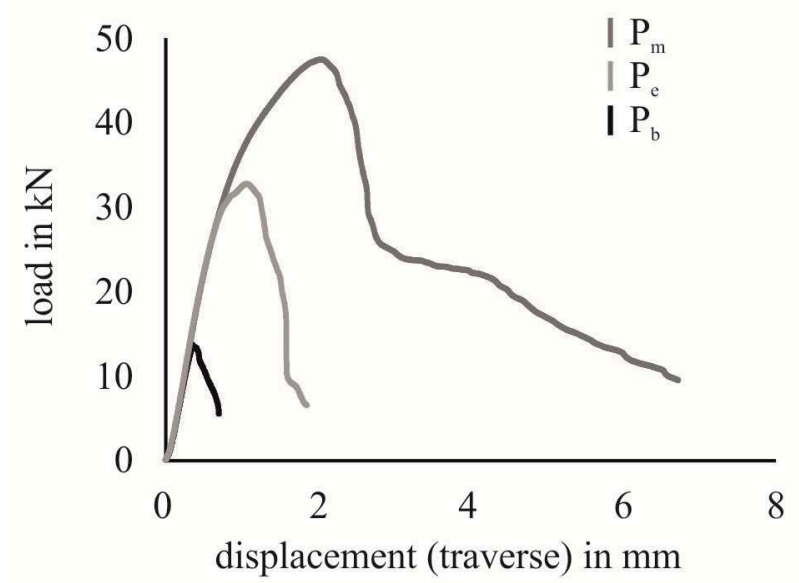

Fig. 7: Load-displacement curves of the push-out test of specimens $\mathrm{P}_{\mathrm{b}}, \mathrm{P}_{\mathrm{m}}$, and $\mathrm{P}_{\mathrm{e}}$ of one hybrid profile

The specimens of the profiles presented bulging of the aluminium matrix near the steel rod after the push-out test. This was due to the asymmetric geometry of the cross-section and could lead to non-uniaxial loading during the test. One of the specimens $\left(\mathrm{P}_{\mathrm{b}}\right)$ showed a comparatively high maximum de-bonding shear strength of $111 \mathrm{MPa}$. The metallographic analysis of this specimen showed a more distinct bulging of the aluminium matrix. In this case, the steel rod was pushed into the aluminium matrix because of a non-parallel sample preparation. Therefore, the steel rod sheared off matrix material during the push-out test, which led to an increased de-bonding shear strength. Hence, this value had to be excluded for the calculation of the averaged value for the $\mathrm{P}_{\mathrm{b}}$ specimens. By this means, an averaged de-bonding shear strength of $18 \mathrm{MPa} \pm 16 \mathrm{MPa}$ was determined for the remaining $\mathrm{P}_{b}$ specimens of the hybrid profiles. For the $\mathrm{P}_{\mathrm{m}}$ specimens, a value of $100 \mathrm{MPa} \pm 3 \mathrm{MPa}$, and for the $\mathrm{P}_{\mathrm{e}}$ specimens a value of $82 \mathrm{MPa} \pm 14 \mathrm{MPa}$ were calculated. The $\mathrm{P}_{\mathrm{m}}$ specimens as well as the $\mathrm{P}_{\mathrm{e}}$ samples exhibited comparable aluminium bulging.

In compliance with these results, the light microscopic analysis showed that there was no strong joint between aluminium and steel at the beginning of the profiles. Furthermore, the steel rod was tilted in one of the hybrid profiles, which led to a falsified value for the de-bonding shear strength, as mentioned above. The highest values for the de-bonding shear strength were determined in the middle of the profiles, which also exhibited low deviation in the averaged value. Here, comparable 
curves for the load-displacement graphs were investigated. At the end of the profiles, the debonding shear strength showed lower values than the $\mathrm{P}_{\mathrm{m}}$ specimens taken from the middle of the profiles. As demonstrated in Fig. 2, the steel rod is supported by a rigid channel in the die during the LACE process in the beginning as well as in the middle of the co-extrusion procedure. Towards the end of this process, the steel rod is embedded in the aluminium matrix inside the welding chamber, without any further stabilisation from to the supporting channel of the die. Thus, a changed aluminium flow can be expected in the final phase of the process, which influences the formation of the material interface. An intermetallic phase between aluminium and steel was not detected over the entire length. Due to the non-coaxial position of the steel rod in the aluminium matrix, a uniaxial loading of the push-out specimen was not ensured. Hence, mechanical clamping was determined as the main bonding mechanism.

\section{Summary and Conclusions}

Based on the results presented in this study, the following conclusions can be drawn:

- After an extrusion length of $20 \mathrm{~mm}$ of the aluminium cladding, laterally symmetric weld seams were present in the cross-sections of the hybrid profiles. However, microscopic gaps between the aluminium matrix and the steel reinforcement existed over the entire length of the profiles. Pre-heating of the steel could be a viable approach for enhancing the bonding between aluminium and steel.

- The tensile tests for the characterisation of the weld seam showed comparable maximum tensile strengths over the entire length as well as to the reference specimens consisting of EN AW-6082. Partially, the tensile specimens failed in the aluminium matrix next to the weld seam. Thus, it can be assumed that the weld seam is not critical for the mechanical properties and the subsequent die forging process.

- The push-out specimens showed asymmetric bulges due to the non-coaxial position of the steel rod and, hence, a not-uniaxial loading of the samples. Therefore, a porthole die is planned for the co-extrusion with the steel rod supported to the die for a symmetric semifinished product. The highest values for the de-bonding shear strength were achieved at the middle of the profiles $\left(\mathrm{P}_{\mathrm{m}}\right)$ with an averaged value of $100 \mathrm{MPa} \pm 3 \mathrm{MPa}$.

\section{Acknowledgements}

The results presented were obtained within the subproject A1 "Influence of local microstructure on the formability of extruded composite profiles" of the Collaborative Research Centre 1153 "Process chain to produce hybrid high performance components by Tailored Forming". The authors thank the German Research Foundation (DFG) for their financial support.

\section{References}

[1] B.-A. Behrens, A. Bouguecha, M. Vucetic, A. Huskic, J. Uhe, C. Frischkorn, T. Matthias, A. Stakhieva, D. Duran, S.E. Thürer, O. Golovko, C. Klose, Umformtechnische Herstellung hybrider Lagerbuchsen, wt werkstattstechnik online 106 (2016) H. 10, 743-748.

[2] C.G. Kang, N.H. Kim, B.M. Kim, The effect of die shape on the hot extrudability and mechanical properties of $6061 \mathrm{Al} / \mathrm{Al} 2 \mathrm{O} 3$ composites, Journal of Materials Processing Technology 100 (2000) 53-62.

[3] M. Kleiner, M. Schomäcker, M. Schikorra, A. Klaus, Herstellung verbundverstärkter Aluminiumprofile für ultraleichte Tragwerke durch Strangpressen, Materialwissenschaft und Werkstofftechnik 35 (2004) H. 7, 431-439. 
[4] N. Grittner, B. Striewe, A. von Hehl, M. Engelhardt, C. Klose, F. Nürnberger, Characterization of the Interface of Co-Extruded Asymmetric Aluminum-Titanium Composite Profiles, Mat.wiss. u. Werkstofftech. 45, (2014) 1054-1060.

[5] D.B. Marshall, An Indentation Method for Measuring Matrix-Fiber Frictional Stresses in Ceramic Composites, J. Am. Ceram. Soc. 67 (1984) C259-C260.

[6] K.A. Weidenmann, E. Kerscher, V. Schulze, D. Löhe, Characterization of the interfacial properties of compound-extruded lightweight profiles using the push-out-technique, Materials Science and Engineering A 424 (2006), 205-211.

[7] K. Hockauf, M.F.-X. Wagner, T. Halle, T. Niendorf, M. Hockauf, T. Lampke, Influence of precipitates on low-cycle fatigue and crack growth behavior in an ultrafine-grained aluminum alloy, Acta Mater. 80 (2014), 250-263. 